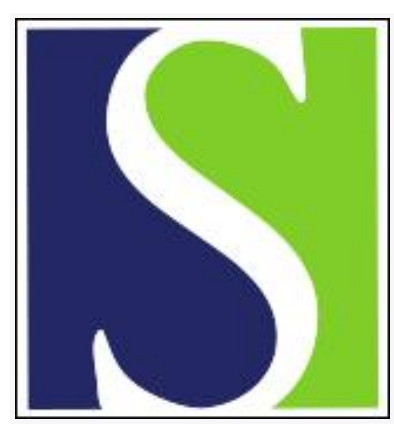

Scand J Work Environ Health 1989;15(6):424-429

https://doi.org/10.5271/sjweh.1831

Issue date: Dec 1989

A comparison of exposure estimates by worker raters and industrial hygienists.

by Teschke K, Hertzman C, Dimich-Ward H, Ostry A, Blair J, Hershler R

Affiliation: Department of Health Care and Epidemiology, University of British Columbia, Vancouver, Canada.

This article in PubMed: www.ncbi.nlm.nih.gov/pubmed/2617258

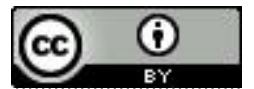




\title{
A comparison of exposure estimates by worker raters and industrial hygienists
}

\author{
by Kay Teschke, MPH, CIH, ${ }^{1}$ Clyde Hertzman, MD, MSc, FRCPC ${ }^{1}$ Helen Dimich-Ward, MSc, ${ }^{1}$
} Aleck Ostry, MSc, ${ }^{1}$ Jim Blair, BA, COHST, ${ }^{2}$ Ruth Hershler, MSc ${ }^{1}$

\begin{abstract}
TESCHKE K, HERTZMAN C, DIMICH-WARD H, OSTRY A, BLAIR J, HERSHLER R. A comparison of exposure estimates by worker raters and industrial hygienists. Scand $J$ Work Environ Health 1989;15:424-429. The validity and reliability of nine senior sawmill workers' estimates of frequency, duration, and routes of exposure were compared with individual workers' ratings of their own job titles and industrial hygienists' ratings of all job titles in the plant. The reliability of the senior workers' mean exposure estimates [group intraclass correlation coefficient $(\mathrm{ICC})=0.71$ ] compared favorably with those of three pairs of hygienists (group ICC $=0.57,0.67$, and 0.81 ). The validity of their ratings was assessed in a comparison with urinary chlorophenate measurements representing $92 \%$ of the job titles in the sawmill. The senior workers' ratings [coefficient of determination $\left(R^{2}\right)=0.22$ ] resembled those of two pairs of industrial hygienists $\left(R^{2}=0.24,0.22\right)$ and was significantly greater than that of the third pair $\left(R^{2}=0.08\right)$. The validity of the self-reports was also low $\left(\mathrm{R}^{2}=0.15\right)$, but the difference was not statistically significant. Senior workers' exposure ratings appear to be as effective as the other methods tested.
\end{abstract}

Key terms: chlorophenols, epidemiologic methods, retrospective studies, reliability, validity.

Documenting of historical exposures is a major difficulty encountered in the retrospective study of chronic occupational diseases. Quantitative data are rarely available from past hygienic surveys $(1,2)$. Generally, prior exposures must be estimated from historical data gathered at the time of the study. Estimates of past exposures are often made by industrial hygienists or other occupational health professionals from within the study team (3-6) or from the industry in question (3). Workers have also been asked to estimate their own exposures $(4,7,8)$.

Our study was undertaken as part of a retrospectivè cohort investigation of the mortality and cancer incidence of chlorophenate-expused sawmill workers. The only exposure-related_data about the sawmill employees which was routinely recorded and preserved during the study period was job title information. Methods used to translate job title data into exposure estimates in other studies were judged to be impracticable in the context of this study. No quantitative data about exposures in sawmill jobs were routinely collected until the end of the study period. Current data could not be used as a surrogate for past exposures because the exposure patterns changed during the period. Occupational health professionals were not em-

\footnotetext{
1 Department of Health Care and Epidemiology, University of British Columbia, Vancouver, British Columbia, Canada.

2 Respiratory Division, Department of Medicine, University of British Columbia, Vancouver, British Columbia, Canada.
}

Reprint requests to: Ms K Teschke, Department of Health Care and Epidemiology, James Mather Bldg, University of British Columbia, Vancouver, BC, Canada V6T 1W5. ployed in the industry until recently and were therefore not familiar with earlier mill conditions. Finally, the study design did not involve contacting individual workers; therefore having each employee estimate his own exposure was not feasible.

For these reasons, a new method of estimating exposure was developed. It used about 10 senior workers to rate the frequency, duration, and route of exposure for all job titles in the sawmill. Using comparisons to urinary chlorophenate levels and interrater agreement, we tested the validity and reliability of the method in one sawmill (9). To explore further the method's operating characteristics, we extended the evaluation to another sawmill and report the results in this paper. Senior workers' estimates of current exposure were compared with those of industrial hygienists and individual workers' self-reports. Although neither of the latter two groups could be used for retrospective exposure assessment in the cohort study, they represent theoretical alternatives against which our method should be judged.

\section{Subjects and methods}

The study sawmill employs 268 hourly workers in 73 job titles. Water-based solutions of sodium tetra- and pentachlorophenate are applied in spray booths in the planer mill and at the timberdeck in the sawmill itself. The mill has a large maintenance staff, many of whom may be exposed to the chemical. Other mill departments, including a boom area, dry kiln, powerhouse, loading shed, and lumber storage yard, have various potentials for exposure. 


\section{Measurement of chlorophenate exposure}

Chlorophenates, as used in sawmills, may be absorbed both by inhalation and through the skin $(10,11)$, and they are largely excreted in the urine $(12,13)$. In order to establish a reference against which to evaluate the exposure estimates, we asked all the workers in the plant to volunteer urine samples over a seven-week period during the fall of 1987 . Grab samples were collected on Thursdays to reflect exposure over the previous several weeks with some influence due to recent daily fluctuations, since estimates of the excretion halftimes of tetra- and pentachlorophenate vary from several days to about two months (14). All the samples were collected in silanized amber jars (15).

The analysis for total chlorophenates (tetra- and penta-) was carried out according to method 3412 of the Workers' Compensation Board of British Columbia (16). An aliquot of each sample was hydrolyzed, then neutralized and buffered. Tribromophenol was added as an internal standard. The solution was allowed to react with acetic anhydride, and the acetylated phenol derivatives were extracted in isooctane. The halogenated phenols were quantitated with the use of a Varian 3300 gas chromatograph fitted with a Supelco SPB-5 capillary column and an electron capture detector.

Each urine sample volunteer was asked to complete a self-administered questionnaire about his usual job, actual jobs held in the eight weeks before sampling, time off in the eight weeks before the sampling, and the personal protective measures normally employed. Each worker was also asked to estimate his own exposure over the previous eight weeks using the same question format as that answered by the senior workers and hygienists estimating exposures for all job titles.

\section{Estimation of chlorophenate exposure by workers and hygienists}

Fifteen senior workers, randomly selected from those with more than five years' seniority at the mill, were individually interviewed about the frequency, duration, and route of exposure for every job in the sawmill. The interviewees were not informed of the content of the interview in advance, and the interviews were conducted in a controlled manner to prevent interaction between the respondents. Of the 15 interviews, six were excluded on the basis of a priori criteria, three because the workers were unable to answer questions about at least $85 \%$ of the job titles and three because the workers gave identical answers for all the job titles. The nine qualifying senior worker raters had held an average of 11 jobs in the mill and had an average of 19 years of seniority.

Three pairs of hygienists were also interviewed. One pair inspected sawmills for a regulatory agency, two worked primarily in the lumber industry, including sawmill operations, and two were from other industries which do not include sawmill operations. Each pair acted as a "rating team," as has been used in other studies $(3,4,8)$. In preparation for the interview, each team was given a list of the mill job titles and a list of the exposure rating questions. Then each pair was given a tour of the sawmill during which they were allowed to ask questions of any worker or supervisor. The tours lasted as long as each team felt necessary. Each hygienist was then interviewed individually in the same manner as the senior worker raters. Of the six industrial hygienists interviewed, one was unable to answer questions about $16 \%$ of the jobs. In order to retain the pair structure, that interview was retained for the analyses of the hygienist groups.

During the interviews, the job titles were presented in random order to prevent bias due to the sequence of questioning. The exposure questions about each job were objective in nature and had a consistent format. The frequency of exposure for a typical individual in each job was categorized as daily, several times a week, several times a month, several times a year, or never. If frequency was rated as greater than never, the duration of exposure on a typical exposure day was estimated as $>7 \mathrm{~h}, 5-7 \mathrm{~h}, 3-5 \mathrm{~h}, 1-3 \mathrm{~h}$, and $\leq 1 \mathrm{~h}$. Finally, the route of exposure was rated as presence or absence of skin exposure, vapor inhalation, and inhalation of contaminated sawdust. The frequency and duration estimates were multiplied to form a continuous exposure estimate in "hours of exposure per year" (9).

\section{Data analysis}

All data analyses were performed using SPSS-X (SPSS = statistical package for the social sciences). The reliability of the raters' estimates of the chlorophenate exposure were assessed with the use of intraclass correlation coefficients derived from a two-way analysis of variance $(17,18)$. The validity of the raters' estimates was assessed with the proportion of variance explained $\left(R^{2}\right)$ by a linear relationship between the measured urinary chlorophenate concentrations and the raters' mean estimates of exposure for the job titles.

\section{Results}

\section{Descriptive data}

Urine samples and self-administered questionnaires were completed by 226 workers in 67 jobs, $84 \%$ of the work force and $92 \%$ of the job titles being represented. One urine sample was excluded from the analysis because the donor was taking a chlorinated pharmaceutical for diabetes which co-chromatogrammed with tetrachlorophenate. The urinary chlorophenate concentrations of the remaining 225 samples ranged from 2 to $989 \mu \mathrm{g} / \mathrm{l}$, with a mean of $99 \mu \mathrm{g} / \mathrm{l}$, a geometric mean of $43 \mu \mathrm{g} / \mathrm{l}$, and a geometric standard deviation of 3.6. The distribution was approximately log normal; therefore the concentrations were expressed as logarithms in all the analyses. A random 


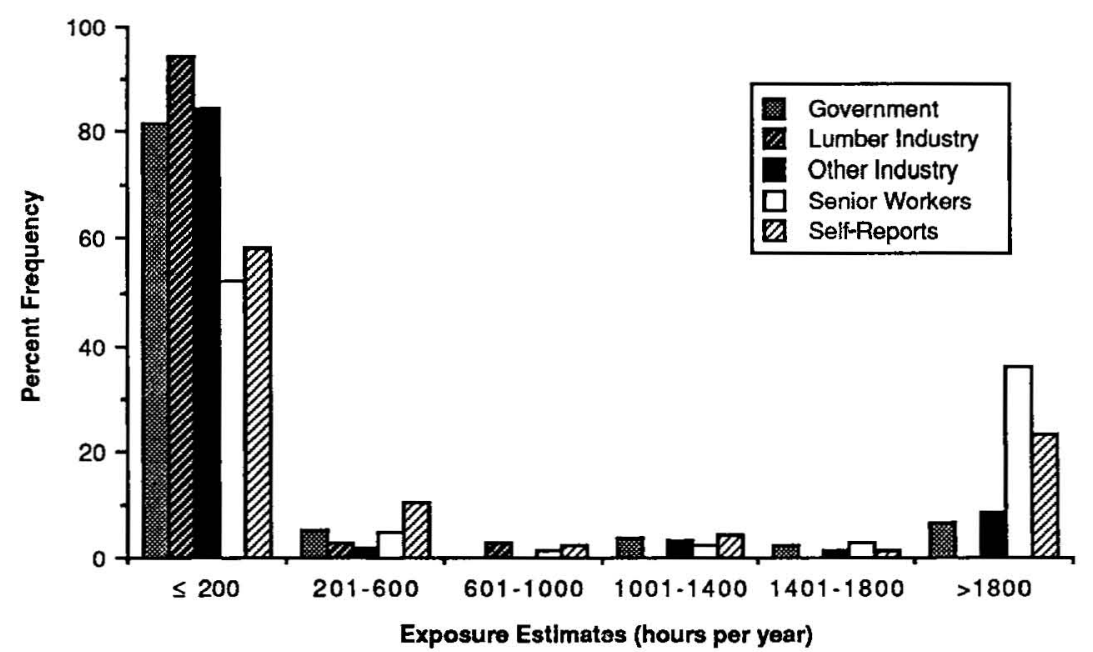

Figure 1. Distributions of the job title exposure ratings made by the government hygienists, lumber industry hygienists, other industry hygienists, the urine sample volunteers (selfreports), and the senior workers.
Table 1. Reliability analyses - intraclass correlation coefficients (ICC) for rater groups' estimates of hours of exposure per year for each job title.

\begin{tabular}{lcc}
\hline Rater group & $\begin{array}{c}\text { Individual } \\
\text { ICC }\end{array}$ & $\begin{array}{c}\text { Group } \\
\text { ICC }\end{array}$ \\
\hline Senior workers $(\mathrm{N}=9)$ & 0.22 & 0.71 \\
Government industrial hygienists $(\mathrm{N}=2)$ & 0.40 & 0.57 \\
Lumber industry hygienists $(\mathrm{N}=2)$ & 0.68 & 0.81 \\
Other industry hygienists $(\mathrm{N}=2)$ & 0.50 & 0.67 \\
\hline
\end{tabular}

sample of 24 urine samples was reanalyzed by the laboratory where the analytic method was developed. The results agreed within $\pm 20 \mu \mathrm{g} / \mathrm{l}$ for $83 \%$ of the samples, and no directional bias was found.

Figure 1 illustrates the distributions of the job title exposure ratings by the five groups of raters. All of the groups' exposure estimates, except those of the hygienists from the lumber industry, covered the maximum range ( $0-2000 \mathrm{~h} /$ year); those of the hygienists from the lumber industry ranged from 0 to 1000 $\mathrm{h} /$ year. The rater groups' mean estimates of exposure were less consistent, ie, $895 \mathrm{~h} /$ year for the senior worker raters, $592 \mathrm{~h} /$ year for the self-reports of the urine sample volunteers, $396 \mathrm{~h} /$ year for the government hygienists, $371 \mathrm{~h}$ /year for the other industry hygienists, and $69 \mathrm{~h} /$ year for the lumber industry hygienists. Both the volunteers making self-reports and the senior workers rated many job titles at the extreme values of less than $200 \mathrm{~h}$ /year and greater than 1800 $\mathrm{h} /$ year. The hygienists rated most of the jobs at less than $200 \mathrm{~h} /$ year.

\section{Reliability analyses}

The values for the intraclass correlation coefficient (ICC) of the raters' estimates of chlorophenate exposure are reported in table 1 . The reliability analyses could not be performed for the self-reports since each urine sample volunteer rated only his own exposure.
The agreement between raters in a group, as assessed by the "individual" ICC (17), was higher for all three industrial hygienist pairs than for the senior worker raters, an expected result since the hygienists were in smaller groups and were able to consult with their team member.

Since it is the group's mean estimates which have been used to assign exposures to the sawmill jobs, the group ICC (18) is the ICC of most interest in the assessment of reliability. That is, if another group of similar raters had been selected, would their mean estimates of exposure agree with those of the original group? As a result of their high level of individual agreement, the hygienists from the lumber industry had the highest group ICC as well. However, that of the senior worker raters exceeded those of the other two hygienist groups. This result may be explained by the larger number of raters in their group, a factor which would be expected to produce a more stable mean estimate than that of a smaller group with similar or even greater individual agreement levels.

\section{Validity analyses}

Table 2 lists the proportion of variance $\left(\mathrm{R}^{2}\right)$ explained by a linear relationship between the volunteers' measured urinary chlorophenate concentrations and the raters' mean estimates of exposure for the volunteers' job titles. For workers who held more than one job, the raters' exposure estimates were averaged for all job titles held in the eight weeks prior to the sampling (9). Two linear models of the relationship between the exposure estimates and the urinary chlorophenate concentrations were constructed. One was based only on the estimates of hours of exposure per year, and the other also included route of exposure ratings.

In the first model, the government hygienists had the highest $\mathrm{R}^{2}$, followed by the other industry hygienists, and then the senior worker raters. The $\mathrm{R}^{2}$ of the urine sample volunteers and the lumber industry 
hygienists was considerably lower, although only that of the latter group was significantly lower $(\mathrm{P}<0.05)$, as measured by a z-score comparison of the correlation coefficients.

In model 2, the raters' answers to the questions on the route of exposure were included as separate additive parameters. Answers "yes" or "no" to each route of exposure were assigned values of 1 and 0 , respectively, and then averaged for each rater group to give continuous probability estimates for each route of exposure. In the case of the urine sample volunteers, who rated only their own exposure, the route of exposure variables were dichotomous. Hours of exposure per year was forced into the model, and the raters' mean estimates of skin, dust, and vapor exposure were entered stepwise only if they added a statistically significant increase in the explanatory power of the model $(\mathrm{P}<0.05)$. The results were inconsistent. For two rater groups, no route of exposure variables entered the model. Skin was included in three cases, and vapor and dust were included once. The lumber industry hygienists, who had the poorest $\mathrm{R}^{2}$ in the simpler model, had the highest $R^{2}$ after all the route-of-exposure variables were added, a finding suggesting that this group relied more heavily on route-of-exposure information to distinguish between jobs. None of the model $2 \mathrm{R}^{2}$ values were significantly different from the others.

\section{Discussion}

The interpretation of these results depends upon which comparisons are made. Although the reliability results suggest that the industrial hygienists performed somewhat better for the individual ICC, the reliability of the nine senior workers' ratings as a group was comparable to those of the industrial hygienist teams. The latter is the more appropriate comparison since the group consensus values, not the individual ratings, were used as the exposure estimate for each job. For the test of validity, the senior worker raters fared as well as the better hygienist teams.

How do these results compare to those found for the mill studied previously and to exposure estimation methods tested by other investigators? In the earlier study (9), the reliability of the senior worker raters (individual $I C C=0.51$, group $I C C=0.91)^{3}$ and the validity of their ratings (fall, all eight weeks, $R=0.72$, $\mathrm{R}^{2}=0.51$ ) were higher. Several factors may account for this difference. The earlier mill had fewer job titles $(\mathrm{N}=59)$, and therefore it was more likely that each senior worker rater was familiar with them. This possibility is partly confirmed by the fact that only two interviews from this mill had to be excluded due to nonresponse problems. Another difference was the industrial relations atmosphere at the mills. In the mill

\footnotetext{
3 Note: The reported ICC values differ somewhat from those in the earlier paper where a one-way, instead of two-way, analysis of variance was used to calculate them.
}

used in our present study, there was tension concerning chlorophenate use, a factor which may have prompted three interviewees to give identical answers for all jobs. This situation did not occur in the mill studied earlier.

Goldberg et al (3) looked at agreement in exposure coding by industry hygienists and by research-team coders. Average kappas for the agreement ranged from 0.51 to 0.69 , with higher agreement within team coder pairs than within groups of six team coders or between team coders and industry hygienists. Kappa is a categorical analogue to the individual ICC. Those calculated for lumber and other industry hygienists in our study were in the same range, as were those of the senior worker raters at the mill studied earlier.

Several studies have looked at the relationshıp between raters' estimates and exposure measurements. Woitowitz et al (6) compared the job exposure estimates made by members of the study team to dust measurements in the mining industry. doPico (7) compared workers' estimates of personal grain dust exposures to measured levels. In both cases, three hazard categories were used by the raters, and the results were evaluated through comparison of the mean and standard deviation of the dust levels for jobs in each category. The mean dust levels had statistically significant increases with hazard class, but the standard deviations in each upper category overlapped the lower ones. This result could signify either misclassification of certain job titles, or it may reflect the greater variability in exposure in those jobs with potential for high exposures.

A study by Kromhout et al (4) is the most similar to ours. In five small factories, plant supervisors and two industrial hygienists were asked to rate all job titles using a four-point scale of exposure. Workers in

Table 2. Validity analyses - proportion of variance in sawmill workers' urinary chlorophenate concentrations explained by rater estimates of exposure by job title.

\begin{tabular}{lcc}
\hline Rater group & $\begin{array}{c}\mathrm{R}^{2 *} \\
\text { (Model 1a) }\end{array}$ & $\begin{array}{c}\mathrm{R}^{2 *} \\
\text { (Model 2b) }\end{array}$ \\
\hline $\begin{array}{l}\text { Senior worker }(\mathrm{N}=9) \\
\begin{array}{l}\text { Government industrial } \\
\text { hygienists }(\mathrm{N}=2)\end{array}\end{array}$ & 0.22 & $0.239(\mathrm{~S})$ \\
$\begin{array}{l}\text { Lumber industry hygienists } \\
(\mathrm{N}=2)\end{array}$ & 0.24 & $0.244(-)$ \\
$\begin{array}{l}\text { Other industry hygienists } \\
(\mathrm{N}=2)\end{array}$ & 0.08 & $0.259(\mathrm{~S}, \mathrm{~V}, \mathrm{D})$ \\
$\begin{array}{l}\text { Self-reporting volunteers } \\
(\mathrm{N}=225)\end{array}$ & 0.22 & $0.223(-)$ \\
\hline
\end{tabular}

a Model $1: \log [C P]=\beta_{0}+\beta_{1} H / Y$, where $[C P]$ is the urinary chlorophenate concentration in $\mu \mathrm{g} / \mathrm{l}$ and $\mathrm{H} / \mathrm{Y}$ is the mean estimate of hours of exposure per year.

b Model 2: $\log [C P]=\beta_{0}+\beta_{1} H / Y+\beta_{2} S+\beta_{3} D+\beta_{4} V$, where $S$ is the continuous probability estimate of skin exposure, $D$ is the continuous probability estimate of inhalation of contaminated sawdust, $V$ is the continuous probability estimate of inhalation of vapors, and - means no route of exposure variable was included in the model

* All significant at $P<0.05$. 
each plant were asked to rate only their own exposure. Ratings were compared to the logarithm of the measured dust or solvent concentrations, and the results were reported as explained variability $\left(R^{2}\right)$ in a oneway analysis of variance model. They concluded that the hygienists rated exposure better [mean $\mathrm{R}^{2}=0.28$ (hygienist 1) and 0.25 (hygienist 2)] than the others [mean $\mathrm{R}^{2}=0.16$ (supervisors) and 0.22 (workers)]. The performance of the workers might be partly explained by the fact that they were rating only their own jobs, without considering its position relative to others in the plant. In both the mills we have tested, the selfreports of the urine sample volunteers had lower $\mathrm{R}^{2}$ values than ratings of the senior workers, who considered all jobs.

An issue raised by Kromhout et al (4) is the effect of the proportion of exposure variability explained by differences between jobs, as opposed to within jobs. In one factory where the between-job variability accounted for $77 \%$ of the exposure variance, the raters performed better $\left(R^{2}=0.37\right.$ to 0.58$)$ than in other factories where between-job variability accounted for only 31 to 46 of the exposure variance $\left(R^{2}=0\right.$ to 0.27$)$. In the mill used in our present study, the between-job component of variance for urinary chlorophenate concentration was only $30 \%$, a value lower than that of any of the factories reported by Kromhout et al. This difference may explain the low $\mathbf{R}^{2}$ values found in our study (for the nine senior workers 0.22 to 0.24 ). It is interesting to note that in the mill of our earlier study in which the proportion of variance explained was higher $(0.51)$, the between-job variability was higher as well $(42 \%)$.

The question then arises of how the rest of the exposure variance might be explained. Much of the variance in our urine sample values occurred within a job and might have been related to an individual's use of personal protective equipment, their own location in the mill, days off, and use of chlorophenates at home. Since each urine sample volunteer was questioned about these factors, an additional analysis was conducted to determine their importance. Adding all personal protective measures (including hand washing on the job and use of protective boots, respirators, gloves, and aprons) to model 2 gave a statistically significant increase of 0.018 to the variance explained by the senior worker ratings. The small size of the increase is likely because there was little variation in these factors between workers with the same job. Self-reported exposure on the job and days off prior to sampling slightly increased the explained variance, but the differences were not statistically significant. Use of chlorophenate at home added nothing, since so few workers reported such an exposure.

Other sources of variability are the exposure measurements themselves. As demonstrated by the reanalyses of our samples, there was a certain amount of variation in the analytical method for urinary chlorophenate. Many of the urine concentrations in the sam- ple from this mill were low, and therefore variability due to the method would have a profound effect on the ordering of job titles. In the mill of our earlier study, in which urine samples were collected during two seasons, the summer sample included more urinary chlorophenate concentrations greater than $100 \mu \mathrm{g} / \mathrm{l}$, and the proportion of variance explained for this sample (all eight weeks, $\mathrm{R}=0.76, \mathrm{R}^{2}=0.58$ ) was higher than for the fall. In addition, when the summer and fall samples were averaged, the proportion of variance explained by the exposure ratings increased by 0.104 over the fall sample by itself. The exposure raters were asked to make estimates based on a "typical" exposure, and, as such, the ratings should better correlate with urine concentrations averaged over a period of time than with any single measure of dose.

The results of this study indicate that senior workers' job exposure estimates should be equivalent in quality to those of industrial hygienists, and perhaps better than those provided by the self-reports of individual workers. Although more complex modeling of the exposure questionnaire data might allow a higher proportion of the variance to be explained, it may also be that job title information, which, as in many retrospective studies, is the only exposure-related data available for the sawmill worker cohort, must be viewed as an imperfect surrogate measure of dose. Some misclassification is inevitable, and therefore the inconclusive dose-related risk estimates must be interpreted with care.

\section{Acknowledgments}

This project was funded by Health and Welfare Canada (contract 1505) and the Workers' Compensation Board of British Columbia.

We would like to express our appreciation to the workers and management of the sawmill involved for their cooperation throughout the study; to the six industrial hygienists for taking time to participate; and to Ms J Slakov, Mr G Lau, Ms S Kelly, and Mr J Spinelli for their work throughout the data gathering and analysis phases.

\section{References}

1. Dement JM, Harris RL, Symons MJ, Shy C. Exposures and mortality among chrysotile asbestos workers: part 1: exposure estimates. Am J Ind Med 1983;4:399—419.

2. Rice C, Harris RL, Lumsden JC, Symons MJ. Reconstruction of silica exposure in the North Carolina dusty trades. Am Ind Hyg Assoc J 1984;45:689-96.

3. Goldberg M, Siemiatycki J, Gerin M. Inter-rater agreement in assessing occupational exposure in a case-control study. Br J Ind Med 1986;43:667-76.

4. Kromhout H, Oostendorp Y, Heederick D, Boleij JSM. Agreement between qualitative exposure estimates and quantitative exposure measurements. Am J Ind Med 1987;12:551-62.

5. Stewart PA, Blair A, Cubit DA, et al. Estimating historical exposures to formaldehyde in a retrospective mor- 
tality study. Appl Ind Hyg 1986;1:34-41.

6. Woitowitz HJ, Schacke G, Woitowitz R. Ranking estimation of the dust exposure and industrial-medical epidemiology. Staub-Reinhalt Luft 1970;30:15-20.

7. doPico G. Epidemiologic basis for dose-response criteria. Ann Am Conf Gov Ind Hyg 1982;2:189-95.

8. Rosenstock L, Logerfo J, Heyer NJ, Carter WB. Development and validation of a self-administered occupational health history questionnaire. J Occup Med 1984; 26:50-4.

9. Hertzman C, Teschke K, Dimich-Ward H, Ostry A. Validity and reliability of a method for retrospective evaluation of chlorophenate exposure in the lumber industry. Am J Ind Med 1988;14:703-13.

10. Kauppinen T, Lindroos L. Chlorophenol exposure in sawmills. Am Ind Hyg Assoc J 1985;46:34-8.

11. Wyllie JA, Gabica J, Benson WW, Yoder J. Exposure and contamination of the air and employees of a pentachlorophenol plant, Idaho 1972. Pestic Monit J 1975; 9:150-3.

12. Braun WH, Young JD, Blau GE, Gehring PJ. The pharmacokinetics and metabolism of pentachlorophenol in rats. Toxicol Appl Pharmacol 1977;41:395-406.
13. Uhl S, Schmid P, Schlatter C. Pharmacokinetics of pentachlorophenol in man. Arch Toxicol 1986;58:182-6.

14. Kalman DA, Horstman SW. Persistence of tetrachlorophenol and pentachlorophenol in exposed woodworkers. J Toxicol Clin Toxicol 1983;20:343-52.

15. Drummond PB, Van Roosmalen PB, Kornicki M. Determination of total pentachlorophenol in the urine of workers. Int Arch Occup Environ Health 1982;50: $321-7$.

16. Workers' Compensation Board of British Columbia. Laboratory analytic methods: pentachlorophenol and tetrachlorophenol in urine, method \# 3412. Richmond, BC: Workers' Compensation Board of British Columbia, 1987.

17. Fleiss JL. Measuring agreement between two judges on the presence or absence of a trait. Biometrics 1975; $31: 651-69$.

18. Winer BJ. Statistical principles in experimental design. 2nd ed. Montreal: McGraw-Hill, 1971.

Received for publication: 19 April 1989 